\title{
XIII. On the various effects produced by the nature, compression, and velocity of the air used in the blast-furnace
}

\author{
Mr. David Mushet
}

To cite this article: Mr. David Mushet (1800) XIII. On the various effects produced by the nature, compression, and velocity of the air used in the blast-furnace, Philosophical Magazine Series 1, 6:21, 60-70, DOI: 10.1080/14786440008677188

To link to this article: http://dx.doi.org/10.1080/14786440008677188

Published online: 18 May 2009.

Submit your article to this journal $\pi$

山 Article views: 3

View related articles 
fufed medicine and food, and was obliged to be drenched in order to get either down : an emetic and cathartic being premifed, they were all put upon the fame plan; that is, were to take, every three hours, two-thirds of a glafs of frefh porter, with two table fpoonfuls of yeft and the juice of half a lemon; and the food at intervals was the white of eggs, which Dr. Thornton judged of all things were leaft fubject to putrify*, beat up with fome fugar and water, and, as it was the commencement of fummer, ftrawberries were alfo ordered; and without any farther medicine from the apothecary than the emetic and purge, although the woman was at firft obliged to be drenched, yet the and her whole family recovered, and this very rapidly.

Among the poor in St. Giles's nothing is adminiftered by Dr. Thornton, after cleanfing the primæ via, than two table fpoonfuls of yeft in fome porter every two hours; and out of above forty cafes not one has died under this treatment.

XIII. On the various Effects produced by the Nature, Compreffion, and Velocity of the Air ufed in the Blajt-Furnace. By Mr. David Mushet, of the Clyde Iron-lForks. Communicated by tbe Author.

V

II $\mathrm{F}_{\mathrm{S}} \mathrm{it}$ is confidered that in the fnelting operation the reduction of immenfe quantities of materials is effected by a comprefled çurrent of air impelled by the whole power of a blowing machine, the confequences of the change of air, either in quantity or quality, muft be very obvious: when, farther, we contemplate the metal called into exiftence by means of combuition thus exeited; when we confider iron as having the molt powerful afinity for the bafe of that part of the air which maintains combuttion; and when we view the debafed fate to which the metal is reduced by coming into improper contact with it, we mut conclude, that the application of blaft in the manufacluring of iron calls for the

* We know that eggs are kept for a great length of time, and the white, even uncier the heat of the hen's body, does not putrify, and it serves as milk to the erbryo in the egB: 
moft minute and thorough inveftigation. In order to take a comprehenfive view of this fubject, the following divifion will be requifite:-

Ift, The intimate connection which the quantity of blaft bears to the area of the internal cavity of the furnace, and to the nature of the pit-coal.

2d, The various modes by which air is procured, and how thefe refpectively affect the quality of the air.

$3 \mathrm{~d}$, The various changes to which air is fubjected by a change of temperature in the atmofphere, with the confequent effects.

$4^{\text {th, }}$ How far increafed or diminithed velocity and compreffion alter the refults of the furnace.

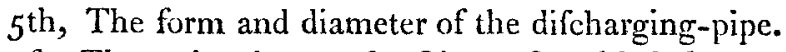

Ift, Then, in the conftruction of a blaft-furnace and blowing-machine, the quantity of air to be ufed ought to depend upon the internal dimenfions of the former; which, again, ought to be formed according to the quality of the pit-coal. Upon the foftnefs or hardners of the coal, ought more immediately to depend the height of the blalt-furnace. This neceffary precaution has given rife to a vaft varicty of furnaces, of different capacities, from 30 to 50 feet in height, and from 9 to 16 feet diameter at the bothes. Furnaces from 30 to 36 feet are ufed for the fofter qualities of coal, fuch as a mixture of free-coal and fplint. Furnaces from $3^{6}$ to 45 are appropriated to the burning of $f_{p}$ lint-coal cokes ; and in Wales, fuch is the fuperior frength and quality of the pit-coal, that the furnaces admit of being reared to the height of 50 feet.

Thefe various qualities of coal, it has been formerly thewn, have appropriate weights of iron-ftone, and, to ufe the language of the manufactory, are capable " of fupporting a greater or leffer burden of mine." The former qualities adnit not of having the air difcharged in great quantity, unlefs it is impelled under an uncommon degree of compreffion and confequent velocity incompatible with the operations of a fteam-engine. The reafon is obvious: when air, loofely compreffed, or comparatively fo, is thrown into a body of ignited fuel, the mechanical ftructure and continuty of whofe 
particles are foft, the air is much more eafily decompofed; the ignition, of courfe, is more rapid : the defcent of the materials is promoted beyond their proper ratio, and long before the carbonaceous matter has penetrated the ore, or united to the metal, to conftitute fufibility. I hall adduce an example, as being moft illuftrative of this doctrine.

Suppofe a blaft-furnace, 35 feet high, I I feet wide at the bothes, properly burdened, and producing No. 1 , pig-iron. Let the difcharge of air be fuppofed equal to a preffure $2 \frac{x}{2}$ pounds upon the fquare inch, or equivalent to $I-6$ th of the atmofphere, or 5 inches of mercury: under thefe circumftances let it farther be fuppofed, that 1500 cubical feet of air are difcharged in one minute; and that the diameter of the difcharging-pipe is 2.625 , the area of which is equal to 6.890625 circular inches. Let the dircharging-pipe be increafed to 3 inches diameter, and let the fame quantity of air be paffed into the furnace; it is evident that as the area of the difcharging-pipe is increafed to 9 circular inches, or nearly $1-3^{d}$ more than formerly, the compreffion of air muft be proportionally diminithed. This alteration is foon perceived by its effects; the quantity of fcoria increales from the furnace, whilf the confumption of the materials above is alfo confiderably augmented. In a few hours the fcoria will have undergone a complete change, from pure white, enamelled with various blue fhades, to a green, brown, or black colour, confiderably charged with the oxyd of iron*. The fame effects will continue, in greater or leffer degree, till all the materials are reduced which were exifting in the furnace at the period of diminithed compreffion. The philofophy of this fact may be accounted for in the following manner:-

While the juft affociation of proportions remained, the air was difcharged under luch a degree of compreffion as to excite proper combuftion: the decompofition of the air by means of the ignited fucl, was not effected in immediate contast with the feparating metal, but had, by its uncommon degree of denfity, refifted decompofition in the ignited paf-

; The metal will have loft nearly all its carbon, and hare become in-

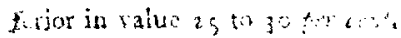


fage, and had been decompofed upon the cokes at a greater elevation in the furnace. As a proof of this, we frequently fee a tube formed throughout the whole breadth of the furnace, quite black and apparently cold, formed of the fufed materials : when this is removed, a confiderable defcent momently takes place of cokes heated vifibly beyond the common pitch : thefe inflame rapidly, but are foon again cooled to blacknefs by the inceffant difcharge of air upon them. The defcending mixture of iron and lava are in like manner couled around the line of blaft; the tube is again formed, and, if not removed, will remain for days together, while the furnace will be otherways working in the beft manner.

When by accident or defign the compreffion and velocity of the blaft are diminithed, the tube begins to burn, and throws off a great many red fiery-coloured fparks, the fides and roof fail, and are carried before the blaft in all directions. Sometimes confiderable cloats of imperfect iron are recoiled with fuch violence as to efcape the vortex of blaft, and iffue from the tuyre-bole with fuch velocity as to inflame in the air, and fall down in the ftate of oxyd. In the end the tuyre will appear to flame, and all the paffage inwards Ahews an aftonifhing degree of whitenefs. The decompofition of the air is inftantaneoully effected upon its entering the ignited paffage; the iron by this means is expofed to the oxygen that is difengaged; and the vaft quantity of caloric fet free, in confequence of its union with the iron and carbon, produces the aftonithing heat now vifible, but which formerly took place at a more proper height in the furnace.

From this it will appear, that although a greater apparent degree of heat is vifibly produced by the fudden decompofition of the air, and a more rapid defcent of materials for fome time is the confequence, yet, as the quality of the iron is impaired, and as in the end the furnace will return to its old confumption of materials as to quantity, the effects of a loofe foft blaft are conclufively pernicious.

It fometimes happens, that when a loofe binft is furcharged with a confiderable portion of moifture, or comes in contact with cokes which had been wet when introduced in to the furnace, the inflammation which takes place at the tuyre is 
prodigious : fine fire-clay will be melted down and blown to Ilag in a fow minutes; the fides of the furnace, compofed of very infufible fire-ftone, is next attacked, and in a few hours will be fo completely deftroyed as to fop the working, and require immediate repair. Effects fimilar to thofe now defcribed will be felt when blaft is improperly proportioned to coal of a ftronger continuity of fracture and fuperior quality. Befides the effects produced by the fudden decompofition of iron, others of like nature are produced where a foft coal is ufed, a fmall furnace, and a great difcharge of blaft.

It has been found that crude iron, to be properly matured, ought to remain in the blaft-furnace, according to circnmftances, 48 to 60 homrs; that is, from the period that the iron-ftone is introduced till fuch time as the metal begins to occupy its place in the hearth in a fate of perfect feparation. When the contrary is the cafe, the mixtures arrive at the hottef parts of the furnace before the metal has taken up a fifficient quantity of carbon from the fuel; the action of the blaft, aind the immediate lieat by which the ore is furrounded, forces the.iron from its connections to the bottom of the furnace. The quality is de-carbonated, and reduced in its value: to reftore this again, the local portion of fuel is increaled; this adds to the expence of mantfacturiry, and diminifhes, in fome nreafure, the fmelting of the furnace.

When filint-coal cokes are ufed in the blatt-fumace, the biat annits of being thrown in under the higheft piffible pitel of compreflion; the uneommon denfity of the charcoal futains a very powerful difcharge of blaft before it is difipated to facilitite the greweral defeent. Moft frequently, large mafles of thefe cinders pals through the whole igrited cavity, and are thrown chit belus, polleng all the acutenefs of their original form and fracture.

This quality of coal is nive in all the Curfon blatt-furnaces, where, to enfure a reipcenble pustue, the air is difcharged moler a prefure equal to $3 \neq$ pounds upon the fquare inch, or 6 inches of mercury.

The fame quality of conl was ufed at the Devon ironwork, whore, at one tine hang all the blaft of a 48 inch cylinker engine thrown into onte furnace, the columin of 
mercury fupported was upwards of 7 inches; the quantity of air difcharged under fuch an impelling power, I found to exceed 2600 cubical feet per minute.

The coals ufed at the Cleugh, Cleland, and Clyde ironworks, are nearly of the fame quality at each-a mixture of fplint and foft coal. The Muirkirk and Glenbixck iron-works have a coal different from any of the former, and in fome particular fpots it confiderably refembles the Englifl clodcoal.

$2 \mathrm{~d}$, The various methods of procuring air for the blaftfurnace may be reduced to the following:-Ift, That procured by cylinders, and difcharged into the furnace by means of a floating pifton heavily loaded, and working in a large recciver or regulating cylinder: $2 \mathrm{~d}$, That wherein pumping cylinders only are ufed, and the air thrown into chefts inverted in water, called the water-vault: $3 \mathrm{~d}$, That mode wherein the air is difcharged from the pumping or forcing cylinder into an air-tight houfe, called the air-vault.

The firft method is the original mode of blowing, and is fill much ufed at thofe iron-works whofe ercetion has been prior to the laft fifteen years. By this mode the quality of the air is lefs fubject to alteration by a change of atmofphere. The principal objection to this manner of blowing, is the want of capacity in the receiving cylinder; which cannot be increafed fo much as to take away the confiderable intervals which occur at different parts of the engine-ftroke. This effect is fenfibly feen by the fpeedy and irregular afcent and defcent of the column of mercury. In water blowing-machines, where the air is raifed by three or four cylinders worked by means of a crank, where the air is received into an air-cheft, and forced into the furnace by the continual action of the blaft of each fucceffive cylinder, the current of air is fteady, and fupports the column of mercury with great uniformity.

The ufe of the water-vault has of late years become very general among new erected works. Its properties are, a fteady and very cold blatt : the largenels of the receiving ciftems gives them a fufficient capacity to retain every pound of air VoL. VI. 
raifed by the furnace, and diftribute it to the greatef advantage. This is not the cafe with the floating piftons, where a certain quantity of fpare wind is thrown out at every retura of the engine, left the great pifton and weight fhould be blown out of the cylinder altogether; which, indeed, fometimes happens. The only objection which remains in force againft the ufe of the water-vault, is the tendency which it has to take up a confiderable portion of the water in folution, and introducing it into the furnace. A judicions arrangement of the conducting-pipes would in fome meafure obviate this, as well as the more dangerous tendency which water has to rife in a pipe fpeedily emptied of its air by the ftopping of the angine: a ftream of water thus conveyed to the furnace, would be productive of the noft awful confsquences.

The air afforded by the air-vault is much inferior to that obtained in the former methods. This immenfe magazine of compreffed air generates a confiderable portion of heat, which greedily feizes the damps, which are unavoidable in underground excavations, and conyeys them to the furnace. The blaft is, however, fteady and uniform; and when the infide of the building is completely fecured againft the paffage of air, it is proctuctive of confiderable effects in the furnace. In the fummer months, however, the air becomes fo far debafed as to affect the quality of the iron, and change it from grey to white. Every change in the temperature of the atmofphere during this pcriod, is indicated by various changes in the furnace.

The largeft air-vault hitherto in ufa was excavated out of folid rock at the Devon iron-works : the fifures of the rock admitted confiderable quantities of water; and the fame degree of damp would always prevent the poffibility of nuking the fide-walls and roof air-tight by means of pitch and paper, \&c.

Befides the various natures of blaft, as to the ftrength and equality of the current afforded by diticrent modes of conftructing the blowing-machines, a variety in the quality of the air obtained is alfo an inyariable confequence: this is 
fafficiently known by the effects which it produces in the blaft-furnace, and ought to be fubject to fcrupulous examination.

In this, as in other countries, larger produces of caft iron are obtained in the winter months than during the fummer and autumn feafons: the quality of the metal is alfo much nrore carbonated, and with a lefs proportion of fuel. In many parts of Sweden, where the fummer heats are intenfe, the manufacturer is obliged to blow out or flop his furnace for two or three months: not only is he unable to make carbonated metal, but is frequently incapalale of keeping the furnace in fuch trim as to make a produce of any quality whatever. In Britain, during the montlss of June, July, and Augutt, more efpecially in dry feafons, the quality of the iron, with the local proportion of fuel, will be depreciated $3 \circ$ per cint., and the quantity reduced to 2 -3ds or 3 -4ths.

In feeking for a folution of this univerfally acknowledged fact, our attention is naturally directed to an examination of the various ftates of air. That the quality of the air in winter is more fit for combuttion than in frmmer, is a truth which requites no further demonleration. Greater coolnefs, wherebs an almoft complete refrigeration of moifture takes place, and the prefence of perhaps a greater relative proportion of exygen, may account for this phenomenon. On the ccntrary, the quality of air during the fummer months becomes moch contaninated for conibuftion, by holding in folution a much greater quantity of moifture: the aburndance of nitreus particks may alf diminifh the ufuit proportion of oxygen.

This will account for the inferior effects of combufion both in common fires and in the blatefurnace; it will alfo in a great meafure tend to folve the euricus phenomenon of pir-iron takitg up lefs carbon in fummer, althongh recluced with a fuperior ghantity of fuel. The air clifcharged moft probutbly contains tets oxygen; get the metal is much lefs carbonated than at other times, when contrary proportions of thefe exift. Nuft probably the deficient carbon is carried off by diflolving in hydrogen, forming a conftant ftream of hivdro-carbonic gas, while the oxygen that is fet free unites 5o ther inn: and while it reduces its quality, at the fame time $\mathrm{K} 2$ the 
the quantity is reduced by a portion of the metal being loft in the fcoria *.

To correct thefe occafional imperfections in the quality of the air, and to devife methods to procure air always fit for proper combuftion, ought to be an object of much confideration to the manufacturer of caft iron. Whether fuch a confideration has given rife to the different modes of receiving and difcharging the air now in ufe, I cannot fay; I rather think not: a great quantity of air has hitherto been a greater object than a certain and uniform quality; and in a country where there is more temperate and cold weather than hot, it is by far the moft important object : to unite both, however, wonld be an attainment of the greateft utility, and would rank the difcoverer amongt the well-deferving of his country. How far the mechanifm of our prefent machinery has been adapted to the exigencies of our atmofphere, will appear upon examining the nature and propertics of the air, judged by its effects upon the blaft-furnace.

The air produced by the blowing and receiving-cylinder is lefs changed, and lefs fubject to change, than that produced and lodged in contact with a vaft body of air or water. If the blowing-cylinder is fixed in a dry cool fpot, the only difference which the air undergoes is an increafe of temperature; this is fo very confiderable, that upon entering the blowing-cylinder immediately after ftopping the, engine, I have found the thermometer rife 15 to $17:$ degrees higher than the furrounding air. That this heat is generated in the cylinder is unqueftionable; but whether it is occafioned by the friction of the pifton leather upon the fides of the cylinder, or expreffed from the air by its fevere compreffion, I have not yet been able to decide. It very probably arifes from both caufes, although the latter is fufficient to product a much greater degree of heat. What effect this increafe of temperature has upon combuftion we are unable to fay, as the degree of heat accumulated will at all times bear a reference to the temperature of the furrounding air, and as

* May not the fuperabundant azote of the fummer atmofphere produce part of the fe eftecls, by diffolving a portion of the carbon, and forming carbonated azotic gas, is has been prored by M. Layoifier? 
there is no method likely to be devifed where heat would not be generated by the action of the particles of air upon each other. When the bulb of a thermometer is held in the middle of the current of blaft, as it iffues from the dilcharging-pipe, a temperature is indicated as much lower than the temperature of the furrounding air, as the temperature of the cylinder was higher; and it is moft probable that a much lower degree would be obtained, were it not for the previous expreffion of fome heat in the blowing-cylinder. Upon the whole, I think, the quality of the air obtained in this way of blowing uniformly moft fit for combuftion, provided the numerous paufes and irregularities of the current of air were done away.

Air forced into the furnace under water prefure always contains a confiderable portion of moifture; the blat of courfe is colder, as it iffues from the difcharging-pipe. The temperature differs fo much from that of the external air as to fink the thermometer from $54^{\circ}$ down to $28^{\circ}$ and $30^{\circ}$. Such effects are produced by air coming into contact with water, that, although the temperature of the atmofphere is 60,65 , to 70 , yet the blaft at the orifice feldom rifes above $3^{8}$ : the cold produced in this manner is much increatid if the air is furcharged with fo much water as to be vinible in the ftate of a fine fpray. The leading feature, therefore, of the watervault, as to its effects upon the quality of the air, fecms to indicate an almoft uniform degree of temperature in the blaft: this can only be occafioned by the warm air in fummer taking up a greater portion of the water in folution, the cfcape of which at a fmall orifice, and under a great degree of compreffion, produces the very great depreffion of the thermometer. I have already hinted at the bad effects prodiceed by moift blafts, and thall, in a proper place, more minutcly attend to them.

The molt inferior quality of air ufed in the blaft-furnace is that thrown into the air-vault, and afterwards expreffed from thence by its own elafticity and the fucceflive ftrokes of the engine. The capacity of fuch a building is from 60 to 70,000 cubical feet; this, when filled, generates a much fuperior degree of heat to that fenfible in the blawing-cylinder. 
As this heat is produced many feet diftant from any mechanical motion, it is moft evident that it is extricated from the air, and will readily unite with the moiture which penetrates the building: the quality of the air introduced into the furnace will therefore be in proportion to the quantity of moifture taken up; this will be much more in fummer than in winter, as the temperature of the former exceeds that of the latter. The fenfation, on entering the air-vault in the coldeft months, immediately after ftopping the engine, is exactly fimilar to that experienced upon entering a crowded room in the hotteft fummer day; the walls are covered with damp, and the fuperior regions of the vath readily obfcure the flame of a candle. The feeling, upon remaining in the air-vant when the engine is at work, is lefs marked than would be expected where fo great a compreffion of air exifted; the fenfe of hearing, owing to the moifture in the conducting medium, is confiderably impaired, and refpiration is performed with fome difficulty; the light of a candle is faint, and not vifible at the diftance of a few feet.

XIV. Some Remarks on the Scotch Dilfillery, and a Defription of an improved Still, wbich, may le cbargid and run off Seventy-two Times in Twuty-fiur Hours *.

$\mathrm{T}$

$\mathrm{HE}$ improvements that have taken place in the common diftillery bufinefs in Scotland within thefe few years are fuch as cannot fail to excite the wonder of men of fcience, while they ferve to prove, at the fame time, that, to infure progrefive improvement in any branch, the moft cffectual mean is that ftimulus which refults from intereft.

It is not neceffary, and it would be tedious, to deferibe the progrefs of the difillery in Scotland, fince it firft began to aflume a form of fome confequence, about twenty years ago. It may, however, not be thought improper to mention what gave occafion to the licence act being introduced into

* Extracted from the Report of the Committee of the Houfe of Commons, July 1799 . 